Supplement of Atmos. Chem. Phys., 19, 5511-5528, 2019

https://doi.org/10.5194/acp-19-5511-2019-supplement

(c) Author(s) 2019. This work is distributed under

the Creative Commons Attribution 4.0 License.

(c) (1)

Supplement of

\title{
Large-scale transport into the Arctic: the roles of the midlatitude jet and the Hadley Cell
}

Huang Yang et al.

Correspondence to: Huang Yang (hyang61@jhu.edu)

The copyright of individual parts of the supplement might differ from the CC BY 4.0 License. 
(a) CO50@30N

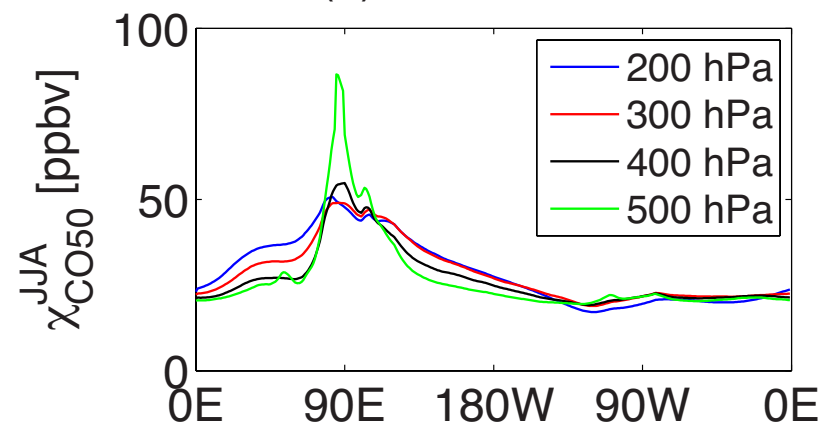

(c) Normalized CMF $(500 \mathrm{hPa}) \& \mathrm{SRC} @ 30 \mathrm{~N}$

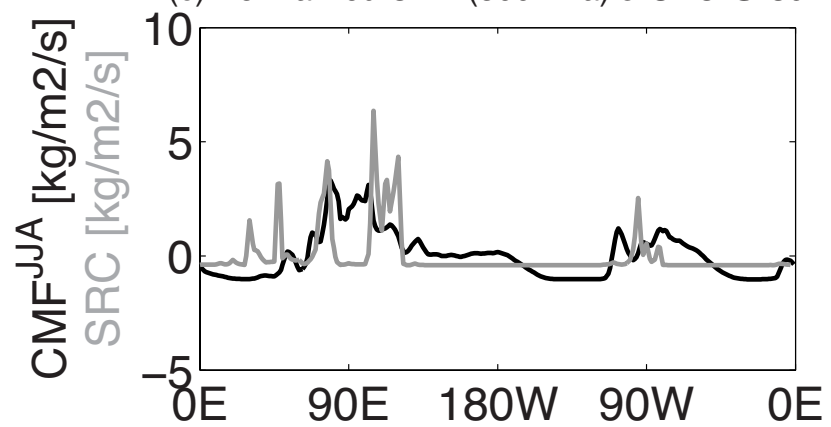

(b) ZM CO50@30N

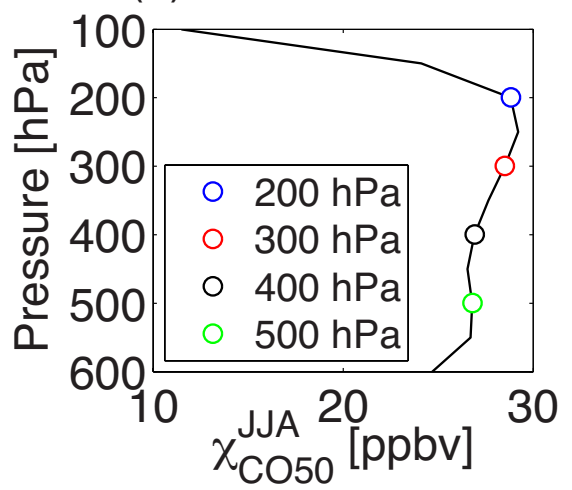

Figure S1. Relations among emission, convection, and CO50 concentration during JJA: (a) longitudinal distribution of CO50 at $30^{\circ} \mathrm{N}$ for various vertical levels from $200 \mathrm{hPa}$ to $500 \mathrm{hPa}$; (b) vertical profile of zonal-mean CO50 concentration at $30^{\circ} \mathrm{N}$ highlighting the values at a few vertical levels that are shown in (a); and (c) $500 \mathrm{hPa}$ CMF (black) and surface CO50 emissions (gray) at $30^{\circ} \mathrm{N}$. 

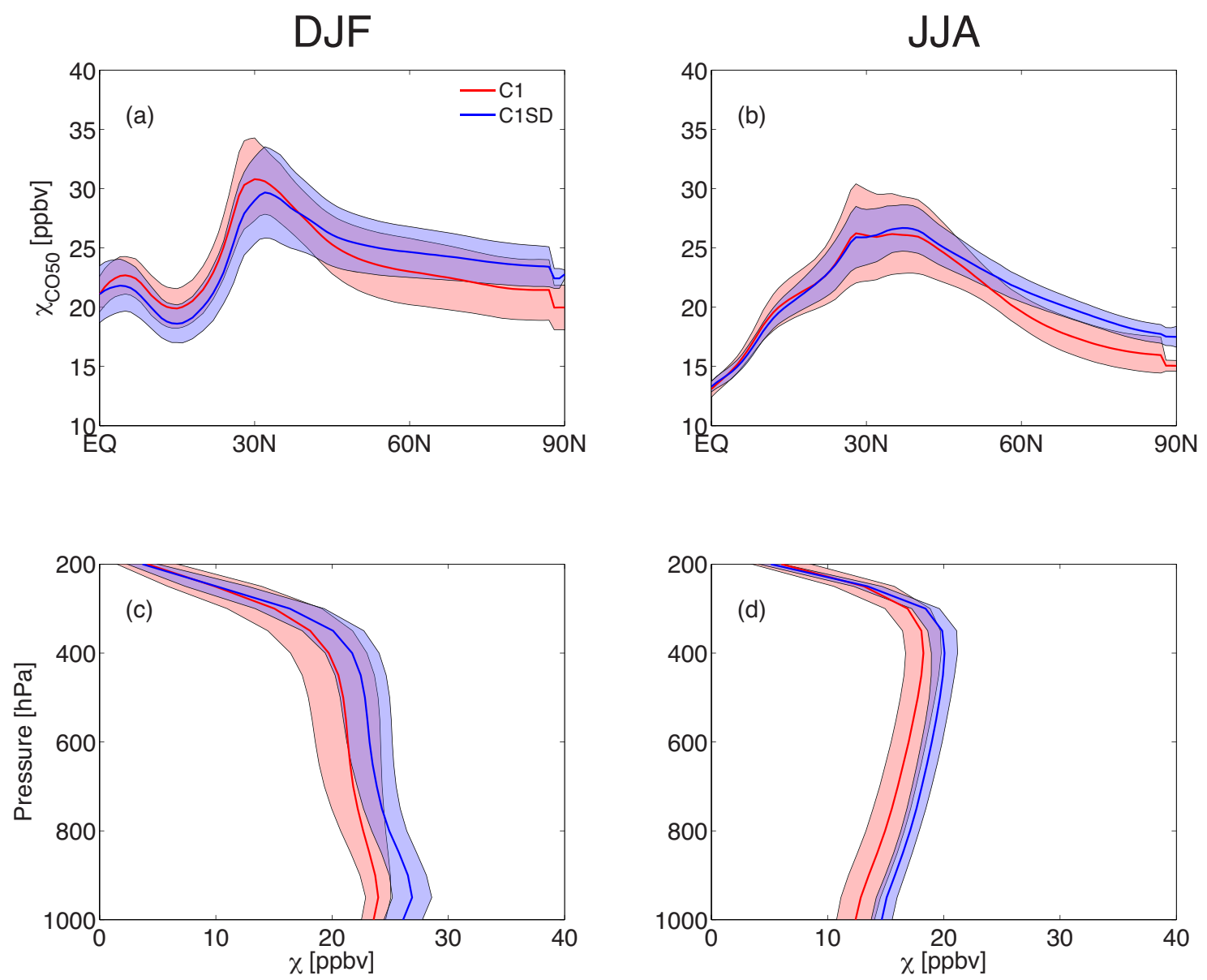

Figure S2. Similar to Fig.2, but showing the multi-model mean of CO50 concentrations in C1 and C1SD simulaitons (red and blue lines respectively), as well as the multi-model spread (denoted by one-standard deviation as shades). 
(a) DJF

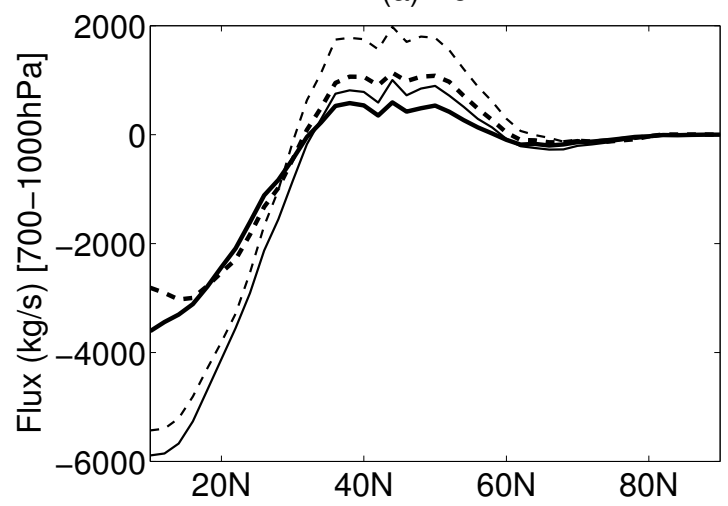

(c)

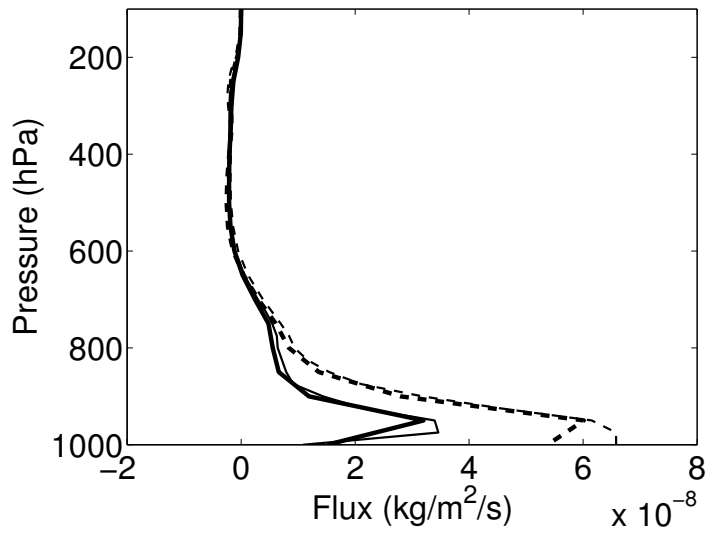

(b) JJA

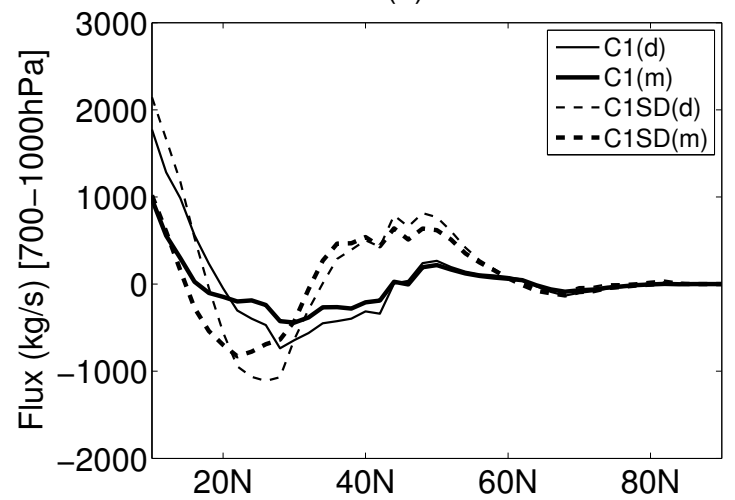

(d)

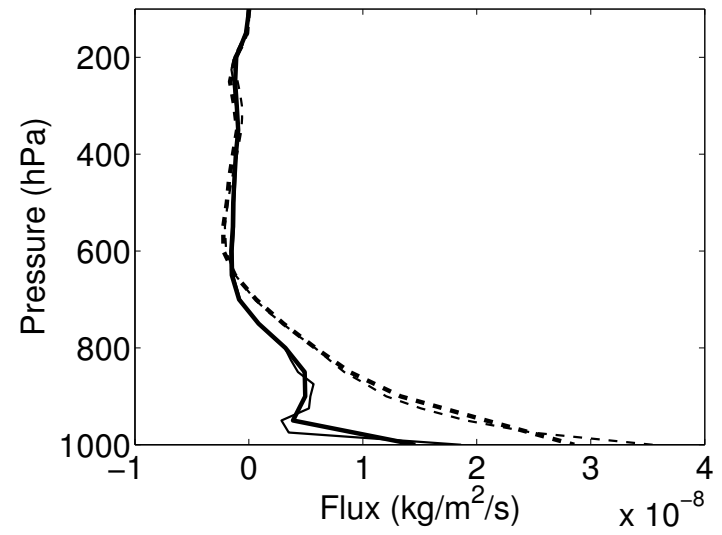

Figure S3. (a,b) Similar to Fig.8, but comparing zonal-mean fluxes in two GEOS simulations (i.e., GEOS-C1 and GEOS-C1SD) derived from daily output (light lines) with ones derived from interpolated monthly output (bold lines) in GEOS-C1 (solid) and GEOS-C1SD (dashed). (c,d) Similar to (a,b), but showing vertical profile of tracer mass flux (units: $\mathrm{kg} \mathrm{m}^{-2} \mathrm{~s}^{-1}$ ) at $50^{\circ} \mathrm{N}$. 

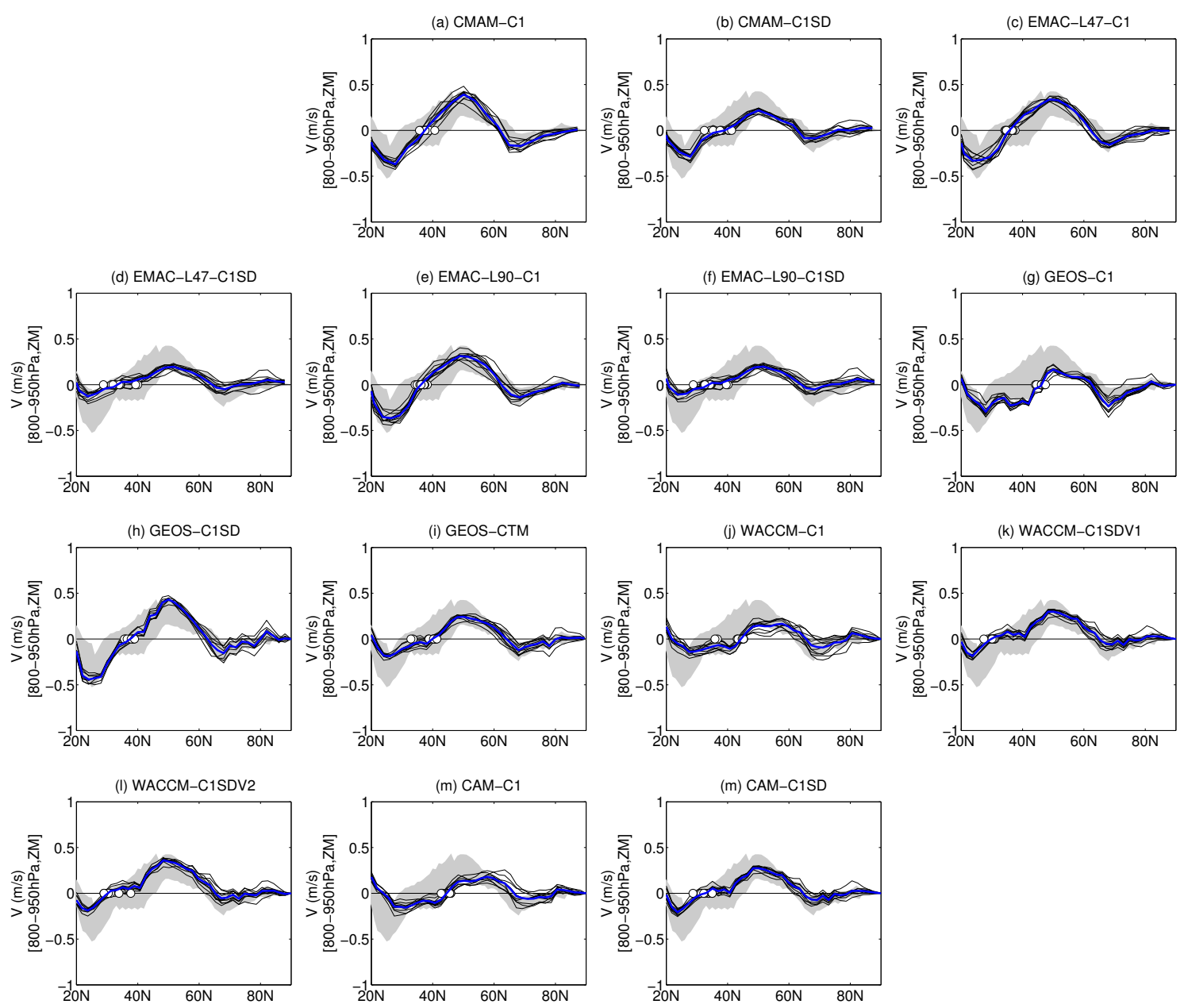

Figure S4. Latitudinal profile of JJA low-level zonal-mean meridional wind $\bar{v}(800-950 \mathrm{hPa})$ in each simulation. The black lines and circles denote the interannual variations of $\bar{v}$ and $\phi_{v=0}$ within the model, while gray shades give the multi-model spread among model climatology, as shown in Figure 10(a). The blue thick line denotes the climatological $v$ of the simulation. 
(a) $850 \mathrm{hPa}, \mathrm{DJF}$

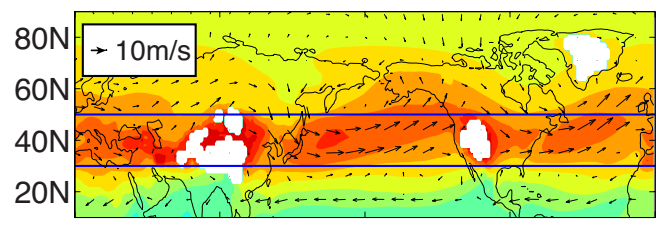

(c) $500 \mathrm{hPa}, \mathrm{DJF}$

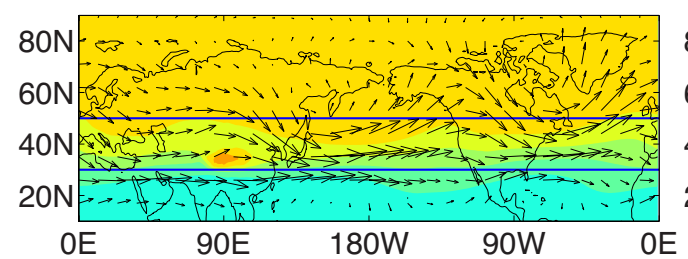

(e) DJF

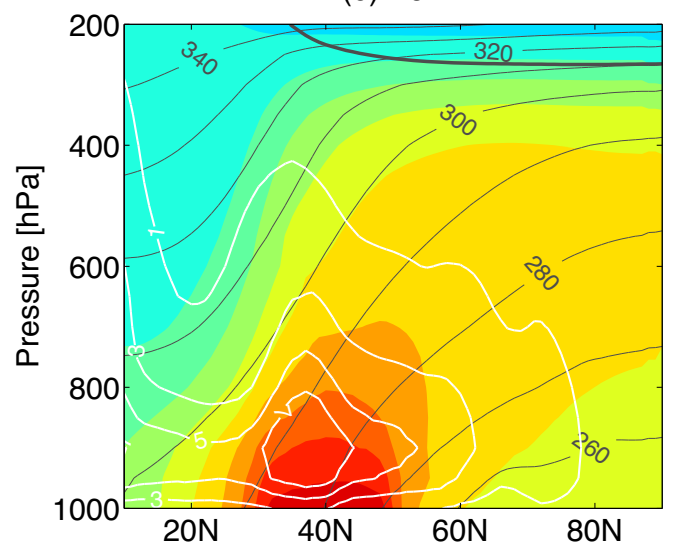

(b) $850 \mathrm{hPa}$, JJA

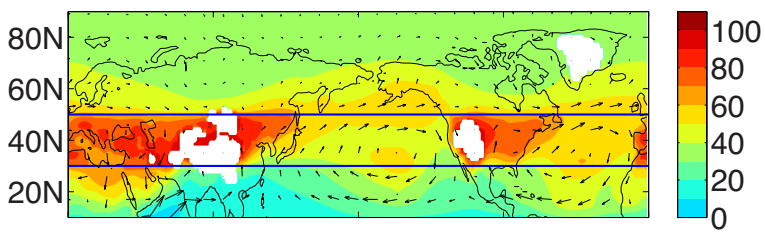

(d) $500 \mathrm{hPa}, \mathrm{JJA}$

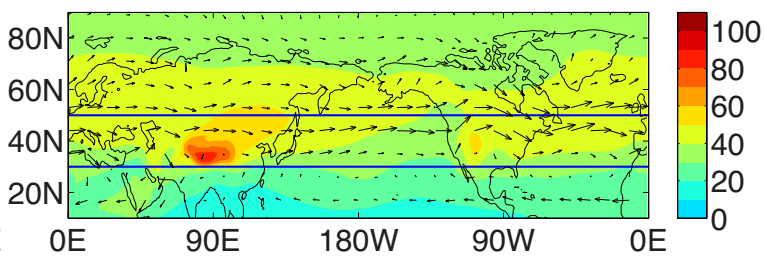

[ppbv]

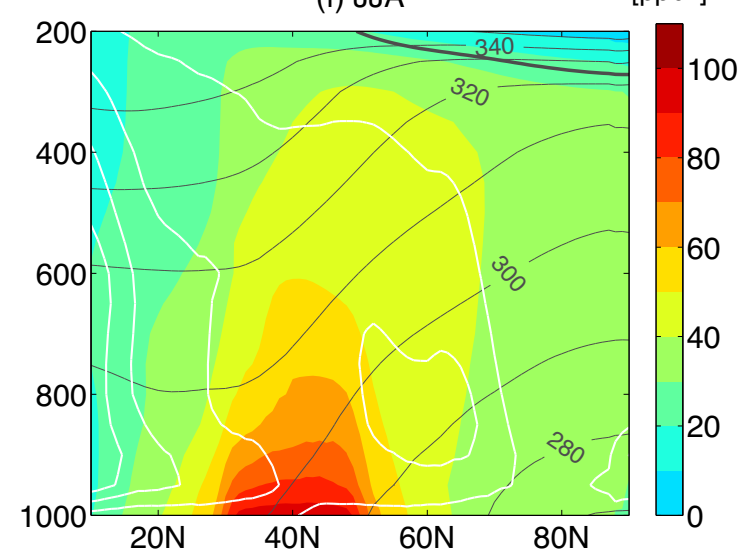

Figure S5. Similar to Fig.1, but for NH50. 
Table S1. Correlation coefficients between Arctic CO50 concentration and physical process related metrics (such as convective mass flux $(\mathrm{CMF}), \phi_{\text {jet }}$, mean flux, and $\phi_{v=0}$ as listed in the $1^{\text {st }}$ column, definitions of metrics followed the same fashion as in the manuscript) calculated using all available models versus only the free-running (C1) models versus clustered models (i.e., exclude NIWA-C1 for similarity to ACCESS-C1, exclude EMAC-L90-C1/C1SD for similarity to EMAC-L47-C1/C1SD, exclude WACCM-C1SDV2 for similarity to WACCMC1SDV1, and exclude CAM-C1/C1SD for similarity to WACCM-C1/C1SDV1). Calculation of correlation is based on climatology, and those are statistically significant $(95 \%)$ are marked in bold.

\begin{tabular}{lcccccc}
\hline & \multicolumn{3}{c}{ DJF } & \multicolumn{3}{c}{ JJA } \\
\cline { 2 - 7 } & All & C1 & Cluster & All & C1 & Cluster \\
\hline CMF & 0.05 & -0.10 & 0.19 & 0.05 & 0.29 & 0.15 \\
$\phi_{\text {jet }}$ & $\mathbf{- 0 . 6 3}$ & $\mathbf{- 0 . 9 2}$ & $\mathbf{- 0 . 6 4}$ & $\mathbf{- 0 . 8 4}$ & $\mathbf{- 0 . 7 9}$ & $\mathbf{- 0 . 8 3}$ \\
mean flux & $\mathbf{0 . 6 9}$ & 0.68 & $\mathbf{0 . 6 9}$ & $\mathbf{0 . 7 8}$ & $\mathbf{0 . 9 6}$ & $\mathbf{0 . 7 9}$ \\
$\phi_{v=0}$ & $\mathbf{- 0 . 7 6}$ & $\mathbf{- 0 . 9 5}$ & $\mathbf{- 0 . 7 6}$ & $\mathbf{- 0 . 5 8}$ & $\mathbf{- 0 . 7 0}$ & $\mathbf{- 0 . 5 1}$ \\
\hline
\end{tabular}


Table S2. Correlation coefficients between mean meridional flux over high latitudes $\left(60^{\circ} \mathrm{N}-80^{\circ} \mathrm{N}\right)$ and Arctic CO50 concentrations $(500-800$ $\mathrm{hPa}, 70^{\circ} \mathrm{N}-90^{\circ} \mathrm{N}$, zonal mean). For mean meridional flux over high latitudes, it is vertically integrated in the low levels (700-1000 hPa) during DJF but in the upper levels (300-500 hPa) during JJA, considering differences in the CO50 vertical maximum between seasons (Fig. 1(e,f) and Fig. 2(c,d)). The correlation between climatologies among models are shown in the $2^{\text {nd }}$ row (similar to results shown in Fig. 9 (b,d)), while interannual correlations in individual simulations are shown in the rows below. Coefficients that are statistically significant (95\%) are marked in bold.

\begin{tabular}{lcc}
\hline Models & DJF & JJA \\
\hline Climatology among models & 0.28 & 0.37 \\
& & \\
CMAM-C1 & $\mathbf{0 . 6 7}$ & -0.26 \\
CMAM-C1SD & 0.35 & $\mathbf{0 . 7 4}$ \\
EMAC-L47-C1 & 0.50 & 0.22 \\
EMAC-L47-C1SD & 0.43 & 0.60 \\
EMAC-L90-C1 & 0.51 & -0.25 \\
EMAC-L90-C1SD & 0.43 & 0.55 \\
GEOS-C1 & $\mathbf{0 . 8 8}$ & $\mathbf{0 . 7 0}$ \\
GEOS-C1SD & 0.12 & $\mathbf{0 . 7 5}$ \\
GEOS-CTM & 0.46 & $\mathbf{0 . 8 4}$ \\
WACCM-C1 & -0.02 & 0.52 \\
WACCM-C1SDV1 & 0.09 & $\mathbf{0 . 7 8}$ \\
WACCM-C1SDV2 & 0.53 & $\mathbf{0 . 8 3}$ \\
CAM-C1 & 0.50 & 0.51 \\
CAM-C1SD & 0.15 & $\mathbf{0 . 7 5}$ \\
\hline
\end{tabular}

